\title{
CHALLENGES FOR JOURNAL EDITORS
}

\author{
Rajeev Kumar Shah ${ }^{1^{*}}$, Sulav Sapkota ${ }^{2}$ Prabin Chhetri $^{3}$ \\ Assistant professor, \\ Department of Otorhinolaryngology, Birat Medical College and Teaching Hospital \\ https://orcid.org/0000-0003-2398-157X
}

\section{Citation}

Rajeev Kumar Shah, Sulav Sapkota, Prabin Chhetri. Challenges for Journal Editors

\section{KEYWORDS: Publishing, Editors, Challenges}

DOI: https://doi.org/10.3126/bjhs.v6i2.40303

Publish or perish is an aphorism describing the pressure to publish academic work in order to succeed in professional career especially at research universities. The value of published work is often determined by the prestige of the academic journal determined by high impact value. All the prestigious journals have one thing in common, which is they all have highly qualified, responsible editorial boards members who adhere to COPE (Committee on Publication Ethics).

Working as an editor for a journal in a low resource countries like Nepal is a challenging job. Though it gives the feeling of being privileged and rewarding, however it is usually an honorary, voluntary work with no financial benefits. The primary aim of the editors is to increase the visibility of research done by researchers and increase the quality of their journal.

BJHS is tri-annual, peer reviewed,double-blinded journal based on open access platform licensed under CC-BY-4.0. Journal editors evaluate all manuscripts that are submitted to our journal, select those which they consider to be suitable for the journal to send for peer review, and consider peer reviewers' advice to make a final decision about what gets published. High quality manuscripts are being published in BJHS regularly and we are working very hard to publish quality articles on the specified time. Due to the large volume of manuscripts being submitted for the consideration of publication, we may have delay in processing the manuscript however authors will have their rights to get updates of their manuscript status. The major challenges we get usually is to get the right person for the external review as per the manuscript subject and to avoid the delay caused due to external review of the manuscript. Sometimes, the content of the manuscript might not be suitable for the consideration of publication and it might require board meeting of editors for final decision..

The Editor is accountable for endorsing the mission of the journal and for accepting original papers that provide noble and prime contributions to research work. The editors themselves may write editorials or may even assign guest editors for special issues. Few qualities that an editor must have are subject expert and a keen eye with command over language. Various skills an editor need to have are good knowledge of English language, excellent verbal communication, being flexible and highly versatile with ability to work well with others.

The editorial board in the journal needs to be author -friendly with suggestions and comments from authors as well as readers to be taken in a positive way for standardization of scientific publications. However at the end, it is the experience of the editor that works always. 